\title{
Yuri Biondi*
}

\section{Accounting for Pandemic: Better Numbers for Management and Policy}

https://doi.org/10.1515/ael-2021-0075

Published online November 10, 2021

\begin{abstract}
Infection, hospitalization and mortality statistics have played a pivotal role in forming social attitudes and support for policy decisions about the 2020-21 SARS-CoV-2 (COVID-19) pandemic. This article raises some questions on some of the most widely-used indicators, such as the case fatality rate, derived from these statistics, recommending replacing them with information based on regular stratified statistical sampling, coupled with diagnostic assessment. Some implications for public health policies and pandemic management are developed, opposing individualistic and holistic approaches.
\end{abstract}

Keywords: non-pharmaceutical interventions (NPI), pandemic management, public health, social statistics

JEL Codes: accounting (M40), Public health (I18), Specific Statistics (C46)

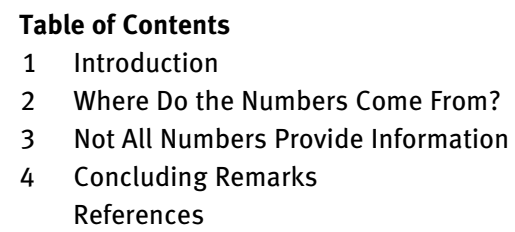

\section{Introduction}

Statistical thinking will one day be as necessary for efficient citizenship as the ability to read and write (Samuel S. Wilks, 1951)

Starting January 2020, public-health authorities, social media and the press reported daily the number of cases, hospitalisations and deaths related to the SARS-CoV-2 (COVID-19 thereafter) pandemic. These numbers have been the focus of public, medical and policy attention, and driven public sentiment towards epidemic and its evolution (Craven McGinty, 2020; Infantino, 2021).

*Corresponding author: Yuri Biondi, CNRS, IRISSO, University Paris Dauphine PSL, Place Marechal Lattre Tassigny, Paris, 75016, France, E-mail: yuri.biondi@gmail.com 
Numbers carry an aura of objectivity, and being scientific. Infection, hospitalizations and deaths statistics appear as facts about the consequences and changing status of the pandemic. Monitoring the current statistics is supported by our urgent wishes to control the pandemic, and forecast its future. These numbers make headline news, ranking high in the critical medical and political decisions on pandemic management (Abbasi, 2020; Asselineau, Grolleaum, \& Mzoughi, 2021). ${ }^{1}$

The problem is that the reported numbers are poor proxies for the underlying phenomenon (Section 1), and they do not deliver reliable information on it (Section 2). Section 1 discusses how reported numbers on the COVID-19 pandemic do not capture its impact and evolution in a reliable and trustworthy manner. Their relationship with the underlying phenomenon is blurred and potentially misguiding. Section 2 addresses the role of those numbers as guidance for decision-making, discussing how properly-accounted numbers may provide relevant and useful information for pandemic management. An overview of the main argument is given in the concluding section.

\section{Where Do the Numbers Come From?}

Daily counting of cases, hospitalisations and deaths gathers the hazardous wish to report on the pandemic as it is, that is, to deliver the full and complete picture about its diffusion in real time. Unfortunately, we do not and cannot know how the virus has been spreading. And even if we knew it, we do not and cannot have sufficient social control over its diffusion to track and count all and every case. And even if an almighty authority had such control, we should yet design an appropriate measurement frame of reference to gather those numbers properly.

No such a thing as a case exists, as such. Case detection depends on the healthcare testing for infected people, and the time and conditions of such testing. Even if reliable tests were available promptly and uniformly over territories, not all the population would be tested every day for contagion; therefore, the number of reported cases depends on the ways tests have been performed, to whom and when. It follows that indicators such as the case fatality

1 To provide just one illustrative example of this number fetishism, the French government provaccination campaign TV spot titled 'the debate' ('Le débat', disseminated since 20 August 2021) deploys the slogan: 'you can argue about everything but numbers' ('On peut débattre de tout sauf des chiffres'). URL: https://youtu.be/iLi5kkTGfRo. 
rate - based upon the ratio between the number of deaths and the number of cases over a certain time window - are misleading and cannot help understanding the ongoing evolution of the underlying epidemic (Brown, 2020).

The number of deceased might appear more solid at the first glance. Nothing seems surer than death and taxes, as the adage goes. But even this number depends on the ways the decease causes are defined and reported. The fact that someone died for medical causes directly related to the COVID-19 disease depends on the healthcare standards which are applicable and the ways these standards have been applied. What if someone died in a car accident while having tested positive for contagion, should this decease be counted? This would imply a broad definition of deceased with the COVID-19 (association). And what if someone died of pneumonia while having tested positive, should this decease be counted? This would imply a narrower definition of deceased due to COVID-19 (causation) including directly related medical complications. Public health authorities have generally chosen to count deceases when a death occurred in a person with a laboratory-confirmed positive COVID-19 test and either: died within 28/60 days of the first specimen date, or COVID-19 was mentioned anywhere on the death certificate (even if not as primary cause), applying indeed a broad definition (Craig, 2021; Heneghan \& Oke, 2020). ${ }^{2}$ No international standard was developed and enforced.

Similar problems occur with the number of either hospital admissions, or people in hospital beds due to or with COVID-19. Their number may include those who tested positive in hospitals, including those already there for other reasons (likely nosocomial infection), and those who had COVID-19 prior to admission and were admitted for other reasons than COVID-19. This counting depends on hospital infection management procedures, and it is further complicated by the origin of admitted people (which could come from nursing or residential care homes), their ongoing treatments and conditions, the overall length of stay and the number of people discharged from hospital with a diagnosis of COVID-19 (Mahon, Jefferson, \& Heneghan, 2020).

2 In fact, when monitoring for SARS-CoV-2 vaccine breakthrough infections, the US CDC COVID-19 Vaccine Breakthrough Case Investigations Team applied a different standard with three mutually exclusive categories (CDC, 2021): asymptomatic cases; patients known to be hospitalized but asymptomatic or hospitalized for a reason unrelated to COVID-19; and hospitalised patients likely due to COVID-19. This latter standard allows sorting out asymptomatic people, while disentangling hospitalisations and deceases unrelated to COVID-19. However, a dualistic distinction between vaccinated and unvaccinated patients - vaccinated patients being counted as such since a certain time lapse after the final dose - does not allow disentangling breakthrough infections and other collateral effects which would occur throughout the individual vaccination process. 
Since the number of cases, hospitalisations and deaths depends on both the testing process and the overarching measurement standards, we should be careful when comparing those numbers through time, as well as across different contexts such as countries. Not to forget the fact that measurement standards have been repeatedly amended over time since the pandemic began.

A look at available statistics shows that the relative number of reported cases over the population in various countries differs widely, as does the relative number of reported deaths. ${ }^{3}$ For instance, mid-September 2020 (mid-June 2021), around 2\% (10\%) of US population tested positive, relative to less than $0.5 \%$ (7\%) in Italy, implying a four-time (+43\%) larger contagion in the former country. Does this difference depend on distinctive contagion diffusion patterns, or just the number of tests and the ways those tests were performed and reported?

Moreover, the case-based lethality rate (that is, the ratio of the number of deceased over the number of reported cases, cumulated through the whole pandemic time window, the latter being dependent on data availability) over the population was around 3\% (1.8\%) in US and 12\% (2.99\%) in Italy. ${ }^{4}$ Was the virus more lethal in the latter, or was this difference resulting from a different way to count for it?

In this context, reports on excess deaths - that is, deaths in excess of previous years or historical patterns - mingle up a combination of deaths that were not properly attributed to COVID-19, plus collateral damage from containment policies (such as undetected medical conditions and postponed medical procedures including screenings). ${ }^{5}$ For instance, a statistical survey by the Italy's Institute of Statistics (ISTAT, 2020a) on mortality over the first trimester 2020 shows that, on total excess deaths (25.354 units), only 54\% were COVID-19 diagnosed (13.710 units).

In a nutshell, we have been counting the ongoing pandemic impact by testing disparate people who carry COVID-19 virus in their upper respiratory tract; but this condition does not tell us much about their underlying medical status, neither the reasons for their hospitalisation or death. In fact, mass testing with low viral

3 Data retrieved from The Johns Hopkins Coronavirus Resource Centre (CRC), https://coronavirus. jhu.edu/.

4 Data retrieved from The Johns Hopkins Coronavirus Resource Centre (CRC), https://coronavirus. jhu.edu/.

5 Mortality in a population is a non-linear phenomenon over time and space. Descriptive statistics may be insufficient to grasp its dynamic. A valid analysis of excess mortality should consider the evolving age structure of population (Toubiana, Mucchielli, Chaillot, \& Bouauda, 2021) and the evolving piling-up of vulnerable people (Herby, 2020), among other factors. 
incidence may certainly lead to an overwhelming number of false positives even though single tests are reliable and properly performed. ${ }^{6}$

Coronaviruses are known to spread rapidly and mutate frequently over time. It is likely that their circulation becomes endemic, notwithstanding pre-existing immune defences, emergent natural immunity from prior infection and vaccination campaigns. For instance, influenza vaccination has been deployed since the 1940s, somewhat protecting vulnerable people without being able to eradicate viral presence and circulation (Montag, 2021). In these circumstances, our current way of counting affords the hazard to keep alerting for the virus prevalence even though its potential danger has diminished and become under control by natural immunities, vaccination and therapies. Imagine if we test for cold all people being admitted to hospitals: We would certainly obtain seasonal waves of persons hospitalised with cold, but this latter circumstance would not add any relevant information about their personal medical condition for public health purposes.

Led by weak and misguiding data-gathering, public health and policy decision-makers enacted draconian measures such as repeated and prolonged lockdowns, disrupting social life. But, at the outset of the pandemic (or at latest about four-six months after it), we had sufficient ex ante knowledge to choose an alternative data-gathering strategy that would have served the societies better. The next section will outline this alternative strategy by addressing the use of numbers for pandemic management and policy.

\section{Not All Numbers Provide Information}

If numbers of cases, hospitalisations and deaths are poor proxies for knowing about the ongoing pandemic impact, should we abandon our wish to gather reliable information about its diffusion? How could we manage our response

\footnotetext{
6 According to Watson, Whiting, and Bush (2020), COVID-19 test sensitivity (proportion of positives that are correctly identified, or true positives) and specificity (proportion of negatives that are correctly identified, or true negatives) are around $80 \%$ and $95 \%$ respectively. Accordingly, a baseline of 10000 random tests on a population with $1 \%$ viral incidence (implying 100 real cases; an illustrative parameter in line with the results of the phase III studies of COVID-19 vaccines, see Montag, 2021) would yield 80 true positives, 20 false negatives, and 495 false positives (5\% of the 9900 negative test results, true negatives being 9405). Therefore, out of the 575 positive test results, only $80(13.9 \%$, the latter being the 'positive predictive value' of such testing) are true positives while $495(86.1 \%)$ are false positives. With low viral incidence (1\%), even a test with $99 \%$ sensitivity and $99 \%$ specificity will generate only a 50\% positive predictive value (all computations were confirmed by the Bayesian Clinical Diagnostic Model at https://kennis-research.shinyapps.io/ Bayes-App/). See also Fenton et al. (2020).
} 
without such information? And since guidance is needed, how can we know about it?

Attention paid to the number of cases, hospitalisations and deaths was based on the naïve belief that we can gather the full picture of the ongoing phenomenon in real time, and even forecast it through time and space. As a matter of fact, some scholars have been pursuing a sophisticated version of this very same line of reasoning. They apply models which demand to track individuals and their social interaction, based upon a key parameter called "effective reproduction number" $\left(R_{\mathrm{t}}\right)$, a pivotal measure of how fast the virus has been spreading. This parameter points to the average number of people who become infected by an infectious person at some point of time. When $R_{\mathrm{t}}$ is above 1.0, the virus will continue spreading over the population; when $R_{\mathrm{t}}$ is below 1.0, the virus will progressively stop its diffusion. This 'individualistic' approach aims to track and control individual behaviour. This focus is consistent with social distancing and social interaction breakdown as policy responses, as well as mass vaccination of the entire population, in view to eradicate virus transmission and circulation.

The problem is that tracking individuals in view to command their social interaction would demand quite an impossible effort, not to mention the violation of liberties and breach of fundamental rights which would be required to perform such effort. In fact, even a less ambitious estimation of that parameter $R_{\mathrm{t}}$ would be so dependent on timing and circumstances that it would not provide but poor guidance for decision-making. To be sure, these models are recent scientific advances fostered by computational capabilities of today. But their overarching reasoning seems inappropriate to provide policy guidance, especially in exceptional circumstances. ${ }^{7}$

At a time when computational capabilities were far more limited, social scientists developed alternative approaches to understand and gather information on social phenomena. Among others, Carl Friedrich Gauss did not become one of the founding fathers of social statistics by tracking individuals throughout a certainly untraceable population. He sampled across the former rigorously, in view to infer reliable information on the latter.

Today, publicly available numbers are poorly defined and have been inconsistently collected. Our overwhelming obsession with case counting, hospitalisation alerts and the death toll is simply meaningless, from a Gaussian perspective. Even research studies have used datasets sampled from patients admitted to hospital, people tested for active infection, or people who volunteered to participate. But Gauss would highlight the struggle of interpreting observational

7 On the role plaid by the "effective reproduction number" (Rt) in COVID-19 management and policy, and its late introduction in epidemiologic studies, see also Miller (2022). 
evidence from those non-representative samples. According to Griffith et al. (2020), 'the problem of collider bias (sometimes referred to as selection bias, sampling bias, ascertainment bias, Berkson's paradox) has major implications for many published studies of COVID-19 and is seldom addressed'.

Instead, what counts would be a reliable estimation of infection diffusion over the whole population, and the correlated risk exposure by certain classes of vulnerable people. This modest approach does not require forecasting the pandemic diffusion in real time, but understanding its featuring patterns as a social phenomenon. At least two statistical indicators would be relevant: the risk for the entire population to develop serious illness and encounter severe outcome, and the lethality rate by relevant classes. By disentangling vulnerable classes, this information would also identify non-vulnerable ones, which do neither get infected (protected by pre-existing immune defences or lack of exposure), nor develop symptoms or serious illness and severe outcome. These indicators may be provided through regular stratified statistical sampling, coupled with diagnostic assessment.

By seeking to track and control individual behaviour, individualistic approaches advocated extreme containment measures such as lockdowns and forced vaccination for all. COVID-19 crisis management has been featured by these extreme containment measures, certainly driven by quite a catastrophic misapplication of the precautionary principle (Bhattacharya, 2021). ${ }^{8}$ Notwithstanding national variants in policy-making, a scare and persuade (and mandate) strategy has been enacted and maintained up to date. ${ }^{9}$

8 In fact, since summer 2021, no precaution was apparently taken when virtually all citizens were pushed to get injected with genetically engineered experimental vaccines, whereas, in 1990, EU political leaders restrained use of genetically modified organisms (GMO) for human food and animal feed (EU Council, 1990). Some public health authorities further deployed campaigns of serial vaccination shots (boosters) certainly aimed to maintain high antibody levels in the population, affording the hazard that antibody-dependent enhancement (ADE) and negative collateral effects may become more likely by repeated mass vaccination for all. Moreover, they pushed vaccination for classes of non-vulnerable people, including when class-specific risk-benefit assessment was uncertain or even contrary to individual well-being. In this context, it is worth remembering that, according to Article 7 of the United Nations' International Covenant on Civil and Political Rights (UN, 1976), "no one shall be subjected without his free consent to medical or scientific experimentation", a principle which cannot be derogated even "in time of public emergency which threatens the life of the nation and the existence of which is officially proclaimed" (Article 4).

9 Just one illustrative example from the minutes and papers by the UK Scientific Advisory Group for Emergencies (SAGE) meeting held on 22 March 2020 (SAGE, 2020), recommending that "the perceived level of personal threat needs to be increased among those who are complacent, using hard-hitting emotional messaging", while foreshadowing measures such as "use media to increase sense of personal threat", "enacting legislation to compel required behaviours" and "use of social disapproval for failure to comply”. See also Kelly (2020) and Rothwell and Desai (2020) on misinformation distorting COVID-19 policies and behaviours. 
Facing ex ante uncertainty about the infection fatality rate, immunities prior and after infection, and the correlates of disease severity, public-health authorities and experts seemed assuming the worst case scenario and acted as if over three out of a hundred infected people will die (Ioannidis, 2021); ${ }^{10}$ immunity prior or after infection does not occur; and virtually all the population is potentially exposed and at serious risk of hospitalization and death after infection. However, holistic approaches were able to timely understand the real threat for the population as a whole, along with the factual risks at stake for identifiable vulnerable people. But their claims for a statistical approach to data-gathering remained isolated and unsuccessful (Finley, 2020; Ioannidis, 2020; Kulldorff, 2020; Lipsitch, Swerdlow, \& Finelli, 2020, interviewing professor Ioannidis; Fenton, Neil, Osman, \& McLachlan, 2020; Lenzer \& Brownlee, 2020; Tierney, 2021a). ${ }^{11}$ At least since spring 2020, information driven from statistically-sound studies was able to reliably identify both the outstanding risk for all, and the relevant classes of vulnerable people, rejecting the worst suppositions behind the forecasting models and their rationale for excess precaution. For instance, a statistical survey by ISTAT (2020b) run between May and July 2020 showed that people who have encountered COVID-19 and showed that estimated seroprevalence was six times higher than the reported cases. ${ }^{12}$ Since April 2020, the UK's Office for National Statistics (ONS, 2021) started running a representative sample testing survey series based on blood test results for antibodies against COVID-19 taken from a randomly selected subsample of individuals aged 16 years and over within the community population (referring here to private residential households, and excluding those in hospitals, care homes and/or other institutional settings). Accordingly, development of serious illness and severe outcome was limited to a tiny share of population, the vast majority of cases being mild or asymptomatic (Jenkins, 2020; Petersen \& Phillips, 2020). Similar studies on mortality showed that increased and excess mortalities have been concentrated on the oldest and fragile people, often already beyond median and mean age at the time of death (longer than their cohort's life expectancy when born), affected by chronic diseases and other comorbidities, and living in healthcare facilities with limited life expectancy. ${ }^{13}$

10 A preprint was made available online at medRxiv since 14 July 2020. DOI: https://www. medrxiv.org/content/10.1101/2020.05.13.20101253v3.

11 Chikina and Pegden (2020) developed a simple model of age-targeted mitigation strategies, published on 24 July 2020. See also Chin, Ioannidis, Tanner, Cripps (2021).

12 ISTAT (2020b) estimated 1501537 infected people (against 243846 persons who tested positive over the same time window), that it, an incidence of $2.5 \%$ over total population (against $0.40 \%)$.

13 Altogether, this information might have fostered an understanding of the syndemic nature of the COVID-19 threat, requiring a "more nuanced approach" in view to protect the health of our communities (Horton, 2021). 
Statistical surveys of incidence and caused severity may provide reliable information on infection incidence, ongoing immunisation by prior immune defence, infection or vaccination, and the likelihood that infection leads to severe forms involving hospitalisation or death. Actual severity may vary depending on strain virulence; healthcare infection management; population structural conditions (especially age and comorbidities as far as COVID-19 is concerned); and exposure. Since an epidemic and its caused severity may spread in non-linear ways, survey sampling may be disaggregated by areas and repeated regularly over time. In a similar way, statistical inference may help generating reliable information on ongoing hospital infection treatment processes and associated outcomes. Possibly, local networks of healthcare institutions may be actively involved in the data-gathering process, contrary to received procedures which appear to rely only on idiosyncratic mass testing, thus neglecting sufficient clinical and laboratory evidence (including post-mortem examination) and bypassing the medical profession.

This 'holistic' approach based upon statistical surveys and inference can generate the relevant and reliable knowledge which is useful for research advancement, policy-making and pandemic management. Public-health authorities may run (and might have run) statistical surveys since the beginning of the pandemic, enabling the scientific community, policy-makers and the citizenry to properly understand its diffusion patterns and emerging risks. Through representative statistical surveys, we can know reliably the factual impact of the ongoing epidemic diffusion over the whole population, and which classes are factually at serious risk. This holistic approach advocates focused protection of vulnerable people, including through voluntary vaccination campaigns, while trusting pre-existing immune defences and emergent natural immunity for non-vulnerable ones.

\section{Concluding Remarks}

'Muor giovane colui ch'al cielo è caro' [Menandro] (Giacomo Leopardi, 1831)

Reviewing the handling of the H1N1 pandemic (the so-called Swine Flu) in 2010, the Parliamentary Assembly of the Council of Europe (CE, 2010, par. 1) was

\footnotetext{
alarmed about the way in which the H1N1 influenza pandemic has been handled, not only by the World Health Organization (WHO), but also by the competent health authorities both at the level of the European Union and at national level. It is particularly troubled by some of the consequences of decisions taken and advice given leading to the distortion of priorities of public health services across Europe, the waste of large sums of public money and unjustified fears about health risks faced by the European public at large.
} 
Since early 2020, a scare-and-persuade (and mandate) strategy has been in place to manage the COVID-19 pandemic. ${ }^{14}$ It resulted in disrupting social interaction, breaching social trust, violating fundamental rights, and spending unprecedented amount of resources, mostly unrelated to providing actual healthcare. ${ }^{15}$ Relying on mass testing and tracing, this strategy has struggled to control and forecast pandemic diffusion in real time. The entire population is sought to be vaccinated in hope of fully eradicating virus transmission, through discriminatory measures against the unvaccinated in many cases.

Daily numbers of cases, hospitalisations and deaths have been an integral part of that strategy. But numbers are not facts. They result from measurement processes which should be carefully considered (and designed) when interpreting those numbers. Not all numbers provide reliable guidance for decision-making, but some of them do it better than others.

Those daily numbers of cases, hospitalisations and deaths are meaningless when we wish knowing what has been going on with the pandemic diffusion. On the contrary, statistical techniques are available to reliably understand its emerging patterns and implied risks. Strategies based upon such a 'holistic' approach would advocate stratified sample testing and focused protection of certain classes of vulnerable people, including their selective vaccination, while relying on mutual trust and the collective emergence of natural immunity for the others (Gupta, 2021). Table 1 provides a dualistic comparison between individualistic and holistic approaches to pandemic management. ${ }^{16}$ On the one hand, individualistic approaches aim to track and control individual behaviour (and then advocate for draconian measures such as lockdowns and forced vaccination for all); on the other hand, holistic approaches aim to understand the whole of pandemic as a social phenomenon, then advocating for focused protection of vulnerable people based upon a holistic understanding.

14 See also Tierney (2021b) on unlearned AIDS lessons for COVID-19 pandemic management, and Ferguson (2021) providing a comparative benchmark with the flu pandemic (so-called 'Asian flu') management of 1957-58.

15 According to $\operatorname{OECD}$ (2021, p. 5), “OECD governments borrowed USD 18 trillion from the markets in 2020, equal to almost 29\% of GDP”. In addition, “central banks in 28 OECD countries purchased government bonds in 2020 with more than half of the net purchases occurring during the period between March and May. Total net purchases by major central banks reached USD 4.5 trillion in 2020, more than half of the new securities (i.e. excluding securities issued to roll over existing debt) issued by OECD sovereigns in the year" (ibidem, p. 15). Central banks further provided material financial assistance to private financial and economic actors, including through those sovereign debt management policies. In this context, Sunder (2021) discussed the impact of central bank liquidity provision on US financial markets.

16 Methodological individualism and methodological holism refer here to methodological and epistemic stances; see also Gupta (2020). 
Table 1: Dualistic overview on alternative approaches to pandemic management.

\begin{tabular}{|c|c|c|}
\hline & Individualistic approach & Holistic approach \\
\hline Approach design & $\begin{array}{l}\text { Individual behaviour and } \\
\text { tracking }\end{array}$ & System behaviour and sampling \\
\hline Accounting framework & Individual tracing and counting & Regular statistical sampling \\
\hline Recommended policies & $\begin{array}{l}\text { Preventative lockdowns and } \\
\text { mass vaccination for all }\end{array}$ & $\begin{array}{l}\text { Focused protection and selective } \\
\text { vaccination of vulnerable people }\end{array}$ \\
\hline $\begin{array}{l}\text { Methodological and } \\
\text { epistemic stances }\end{array}$ & $\begin{array}{l}\text { Methodological individualism, } \\
\text { forecasting purpose }\end{array}$ & $\begin{array}{l}\text { Methodological holism, understand- } \\
\text { ing purpose }\end{array}$ \\
\hline $\begin{array}{l}\text { Overall political } \\
\text { philosophy }\end{array}$ & $\begin{array}{l}\text { Draconian precautionary mea- } \\
\text { sures by authoritarian public } \\
\text { health }\end{array}$ & $\begin{array}{l}\text { Informed management and contain- } \\
\text { ment measures respectful of individ- } \\
\text { ual liberty and responsibility }\end{array}$ \\
\hline
\end{tabular}

Pandemic management and policy require seeking for a balance between individual rights and other people's protection within the same risk class. The vexata quaestio is whether draconian measures such as repeated and prolonged lockdowns and forced vaccination for all do apply excess precaution through measures which are neither strictly required by the exigencies of the situation (necessity) nor proportional to factual risks (proportionality), resulting in violating the former in the name of the latter. Especially once evidence of the real threats at stake for all and each one exists, pandemic may be managed in alternative and less disruptive ways. ${ }^{17}$ And this has been the case since spring 2020 for the COVID-19 pandemic. ${ }^{18}$

17 In this context, it is worth remembering that, in the middle of the COVID-19 pandemic, the Council of Europe's resolution No. 2361 (CE, 2021) asks governments, 'with respect to ensuring a high vaccine uptake', to 'ensure that citizens are informed that the vaccination is not mandatory and that no one is under political, social or other pressure to be vaccinated if they do not wish to do so' (7.3.1); and to 'ensure that no one is discriminated against for not having been vaccinated, due to possible health risks or not wanting to be vaccinated' (7.3.2). According to Article 6 of UNESCO (2005)'s Universal Declaration on Bioethics and Human Rights: 'any preventive, diagnostic and therapeutic medical intervention is only to be carried out with the prior, free and informed consent of the person concerned, based on adequate information. The consent should, where appropriate, be express and may be withdrawn by the person concerned at any time and for any reason without disadvantage or prejudice.' And the Article 5 of the Convention on Human Rights and Biomedicine (CETS, 1997) states that '(i) an intervention in the health field may only be carried out after the person concerned has given free and informed consent to it. (ii) This person shall beforehand be given appropriate information as to the purpose and nature of the intervention as well as on its consequences and risks. (iii) The person concerned may freely withdraw consent at any time.'

18 According to Packalen and Bhattacharya (2021), 'politicians, civil servants, and even scientists now constantly hide behind the "follow the science" mantra rather than admit that science merely 
Neither individuals nor societies can beat the death, eventually. But we can keep living while doing our best effort to cope with old and new diseases, applying sound public health management and policies which respect fundamental rights.

Acknowledgements: I wish thanking Shyam Sunder and two anonymous reviewers for their thoughtful comments and suggestions. Usual disclaimer applies.

\section{References}

Abbasi, K. (2020). COVID-19 politicisation, "corruption," and suppression of science. When good science is suppressed by the medical-political complex, people die. BMJ, 371, $\mathrm{m} 4425$.

Asselineau, A., Grolleaum, G., \& Mzoughi, N. (2021). A good servant but a poor master: The side effects of numbers and metrics. Administration \& Society. https://doi.org/10.1177/ 00953997211043830.

Bhattacharya, J. (2021). On the catastrophic misapplication of the precautionary principle. Collateral Global, Editor's Note - Week Five 14 June. Retrieved from https://collateralglobal. org/article/editors-note-5/.

Brown, R. B. (2020). Public health lessons learned from biases in coronavirus mortality over estimation. Disaster Medicine and Public Health Preparedness, 12, 1-8.

CDC - Center for Disease Control and Prevention. (2021). COVID-19 vaccine breakthrough infections reported to CDC - United States, January 1-April 30, 2021. CDC COVID-19 Vaccine Breakthrough Case Investigations Team, Morbidity and Mortality Weekly Report (MMWR), 70(21). https://doi.org/10.15585/mmwr.mm7021e3.

CE - Council of Europe. (2010). Handling of the H1N1 pandemic: More transparency needed. Parliamentary Assembly Resolution n. 1749. Retrieved from https://pace.coe.int/en/files/ 17889\#trace-3.

CE - Council of Europe. (2021). Covid-19 vaccines: Ethical, legal and practical considerations. Parliamentary Assembly Resolution n. 2361. (5th Sitting). Retrieved from https://pace.coe. int/en/files/29004/html.

CETS - Council of Europe Treaty Series. (1997). Convention on human Rights and biomedicine, European treaty series - ETS No. 164. Oviedo. Retrieved from https://www.coe.int/en/web/ conventions/full-list/-/conventions/treaty/012A?module=treaty-detail\&treatynum=164.

Chikina, M., \& Pegden, W. (2020). Modeling strict age-targeted mitigation strategies for COVID-19. PLoS One, 15(7), e0236237.

Chin, V., loannidis, J. P. A., Tanner, M. A., \& Cripps, S. (2021). Effect estimates of COVID-19 nonpharmaceutical interventions are non-robust and highly model-dependent. Journal of Clinical Epidemiology, 136, P96-P132.

helps us make more informed decisions. We no longer dare acknowledge that-because our choices always involve trade-offs-the virtue of pursuing one course of action over another always rests not just on the knowledge we get from science but also on our values. We have seemingly forgotten that scientists merely produce knowledge about the physical world, not moral imperatives about actions that involve trade-offs. The latter requires understanding our values.' 
Craig, C. (2021). How covid deaths are over-counted, COVID-19 Assembly February 9. Retrieved from https://www.covid19assembly.org/2021/02/how-covid-deaths-are-over-counted/.

Craven McGinty, J. (2020). Counting coronavirus cases: Why it's harder than it might seem. The Wall Street Journal, 17 Apr. Retrieved from https://www.wsj.com/articles/countingcoronavirus-cases-why-its-harder-than-it-might-seem-11587115801.

EU Council. (1990). Council Directive 90/220/EEC of 23 April 1990 on the deliberate release into the environment of genetically modified organisms. OJ L 117, 15-27. (repealed by Directive 2001/18/EC of the European Parliament and of the Council of 12 March 2001 on the deliberate release into the environment of genetically modified organisms and repealing Council Directive 90/220/EEC). Retrieved from http://data.europa.eu/eli/dir/1990/220/oj.

Fenton, N. E., Neil, M., Osman, M., \& McLachlan, S. (2020). COVID-19 infection and death rates: The need to incorporate causal explanations for the data and avoid bias in testing. Journal of Risk Research, 23(7-8), 862-865.

Ferguson, N. (2021). How a more resilient America beat a midcentury pandemic. The Wall Street Journal, 30 Apr. Retrieved from https://www.wsj.com/articles/how-a-more-resilientamerica-beat-a-midcentury-pandemic-11619794711.

Finley, A. (2020). The bearer of good coronavirus news. The Wall Street Journal, 24 Apr. Retrieved from https://www.wsj.com/articles/the-bearer-of-good-coronavirus-news-11587746176.

Griffith, G. J., Morris, T. T., Tudball, M. J., Herbert, A., Mancano, G., Pike L., ... Hemani, G. (2020). Collider bias undermines our understanding of COVID-19 disease risk and severity. Nature Communications, 11, 5749.

Gupta, S. (2020). We may already have herd immunity - an interview with Professor Sunetra Gupta, Reaction, 21 Jul. Retrieved from https://reaction.life/we-may-already-have-herdimmunity-an-interview-with-professor-sunetra-gupta/? fbclid=IwAROucQOKcLEDQNapy0RRFx3TQQ VhiCANyFWZAzmRoUfHVp8BpablTZxceE.

Gupta, S. (2021). Collateral global - CG mini-lectures: Herd immunity, Collateral Global, 28 May. Retrieved from https://collateralglobal.org/article/mini-lecture-herd-immunity/.

Heneghan, C., \& Oke, J. (2020). Public health England has changed its definition of deaths: The COVID-19 response, 12 Aug. Retrieved from https://www.cebm.net/COVID-19/public-healthengland-death-data-revised/.

Herby, J. (2020). Sweden's “Dry Tinder” accounts for many Covid-19-deaths. American Institute for Scientific Research - IAER, 9 Nov. Retrieved from https://www.aier.org/article/swedens-drytinder-accounts-for-many-covid-19-deaths/.

Horton, R. (2021). Offline: COVID-19 is not a pandemic. The Lancet, 396(10255), P874.

Infantino, M. (2021). Hazards and fallacies of social measurements: Global indicators in the pandemic. International Journal of Law in Context, 17, 168-185.

loannidis, J. P. A. (2020). A fiasco in the making? As the coronavirus pandemic takes hold, we are making decisions without reliable data. STAT, 17 Mar. Retrieved from https://www.statnews. com/2020/03/17/a-fiasco-in-the-making-as-the-coronavirus-pandemic-takes-hold-we-aremaking-decisions-without-reliable-data/.

Ioannidis, J. P. A. (2021). Infection fatality rate of COVID-19 inferred from seroprevalence data. Bulletin of the World Health Organization, 99 (1), 19-33F. Preprint at medRxiv, 14 July 2020.

ISTAT. (2020a). Impatto dell'epidemia COVID-19 sulla mortalità totale della popolazione residente primo trimestre 2020 [Impact of COVID-19 pandemic on total mortality of resident population over the first trimester 2020], 4 May. Retrieved from https://www.istat.it/it/files/2020/05/ Rapporto_Istat_ISS.pdf. 
ISTAT. (2020b). Primi risultati dell'indagine di sieroprevalenza sul sars-cov-2 [Preliminary results of seroepidemiological investigation on COVID-19], 3 Aug. Retrieved from https://www.istat. it/it/archivio/256536.

Jenkins, H. W. (2020). The Slow Birth of Covid Realism. Can we now admit that herd immunity and vaccines will work in tandem? Wall Street Journal, 29 Dec. Retrieved from https://www.wsj. com/articles/the-slow-birth-of-covid-realism-11609284003.

Kelly, J. (2020). Covid kills, but do we overestimate the risk? FT Aphaville, The Financial Times, 20 Nov. Retrieved from https://www.ft.com/content/879f2a2b-e366-47ac-b67a$8 \mathrm{~d} 1326 \mathrm{~d} 40 \mathrm{~b} 5 \mathrm{e}$.

Kulldorff, M. (2020). COVID-19 Counter Measures Should be Age Specific. Linkedin, 10 Apr. Retrieved from https://www.linkedin.com/pulse/covid-19-counter-measures-should-agespecific-martin-kulldorff/.

Lenzer, J., \& Brownlee, S. (2020). The COVID Science Wars. Shutting down scientific debate is hurting the public health. Scientific American, 30 Nov. Retrieved from https://www. scientificamerican.com/article/the-covid-science-wars1/.

Leopardi, G. (1831). 'Amore e Morte', Canto XXVII. In A. Donati (Ed.), Canti (1917). Bari: Laterza.

Lipsitch, M., Swerdlow, D. L., \& Finelli, L. (2020). Defining the epidemiology of covid-19-studies needed. New England Journal of Medecine, 382, 1194-1196.

Mahon, J., Jefferson, T., \& Heneghan, C. (2020). Are COVID-19 patients in hospital or admitted to hospital? The centre for evidence-based medicine (CEBM). Evidence Service to support the COVID-19 response, 13 Apr. Retrieved from https://www.cebm.net/COVID-19/are-COVID-19patients-in-hospital-or-admitted-to-hospital/.

Miller, P. (2022). Afterword: Quantifying, mediating and intervening: The R number and the politics of health in the twenty-first century, (Chapter 14). In A. Mennicken, \& R. Salais (Eds.), The new politics of numbers. Utopia, evidence and democracy, Cham, Switzerland: Palgrave Macmillan, (pp. 465-476). https://link.springer.com/content/pdf/10.1007\%2F978-3-03078201-6_14.pdf.

Montag, K. (2021). On the efficacy of influenza and COVID-19 vaccines, Multipolar Magazin, 14 Jun. Retrieved from https://multipolar-magazin.de/artikel/efficacy-of-vaccines.

OECD. (2021). Sovereign borrowing outlook for OECD Countries. Paris.

ONS. (2021). COVID-19 Infection Survey: methods and further information, 26 Mar. Retrieved from https://www.ons.gov.uk/peoplepopulationandcommunity/healthandsocialcare/ conditionsanddiseases/methodologies/ covid19infectionsurveypilotmethodsandfurtherinformation.

Packalen, M., \& Bhattacharya, J. (2021). Lockdown Harms and the Silence of economists, Collateral Global, editorial, 29 Aug. Retrieved from https://collateralglobal.org/article/lockdownharms-and-the-silence-of-economists/.

Petersen, I., \& Phillips, A. (2020). Three quarters of people with SARS-CoV-2 infection are asymptomatic: Analysis of English household survey data. Clinical Epidemiology, 12, 1039-1043.

Rothwell, J., \& Desai, S. (2020). Misinformation is distorting COVID policies and behaviors, research report, the Brookings Institution, 22 Dec. Retrieved from https://brook.gs/ 37DSwwM.

SAGE - Scientific Advisory Group for Emergencies. (2020). Options for increasing adherence to social distancing measures, 22 March 2020. In Paper prepared for the Scientific Advisory Group for Emergencies. SAGE. Retrieved from https://www.gov.uk/government/ 
publications/options-for-increasing-adherence-to-social-distancing-measures-22-march2020.

Sunder, S. (2021). How did the U.S. stock market recover from the Covid-19 contagion? Mind \& Society, 20, 261-263.

Tierney, J. (2021a). The panic pandemic. Fearmongering from journalists, scientists, and politicians did more harm than the virus. City Journal, Summer 2021. Retrieved from https:// www.city-journal.org/panic-pandemic.

Tierney, J. (2021b). Unlearned AIDS lessons for covid. The Wall Street Journal, 3 Oct. Retrieved from https://www.wsj.com/articles/aids-panic-covid-19-coronavirus-pandemic-expertspoliticized-fauci-follow-science-11633290650.

Toubiana, L., Mucchielli, L., Chaillot, P., \& Bouauda, J. (2021). L'épidémie de Covid-19 a eu un impact relativement faible sur la mortalité en France. IRSAN, 25 Mar. Retrieved from http:// recherche.irsan.fr/fr/documentation/index/voir/154-L\%E2\%80\%99\%C3\%A9pid\%C3\% A9mie-de-Covid\%E2\%80\%9119-a-eu-un-impact-relativement-faible-sur-la-mortalit\%C3\% A9-en-France.

UN - United Nations. (1976). International covenant on civil and political rights (ICCPR), adopted and opened for signature, ratification and accession by General Assembly resolution $2200 \mathrm{~A}$ (XXI) of 16 December 1966, entry into force 23 March 1976, in accordance with Article 49. Retrieved from https://www.ohchr.org/en/professionalinterest/pages/ccpr.aspx.

UNESCO. (2005). Universal declaration on bioethics and human rights, 19 Oct. Retrieved from http://portal.unesco.org/en/ev.php-URL_ID=31058\&URL_DO=DO_TOPIC\&URL_ SECTION=201.html.

Watson, J., Whiting, P., \& Bush, J. (2020). Interpreting a COVID-19 test result. BMJ, 369, m1808. Wilks, S. S. (1951). Undergraduate statistical education. Journal of the American Statistical Association, 46(253), 1-18. 